\title{
Usando QRcode no Cenário de Aulas Gamificadas
}

\author{
Jéssica M. da Silva ${ }^{1}$, Micheline B. da Motta ${ }^{2}$ \\ ${ }^{1}$ Universidade Federal de Pernambuco (CAV/UFPE) - Vitória de Santo Antão, PE - \\ Brasil \\ ${ }^{2}$ Centro de Educação - Universidade Federal de Pernambuco (UFPE) - Recife, PE - \\ Brasil \\ jessprofbio@gmail.com, biomotta@yahoo.com.br
}

\begin{abstract}
Asssociating innovative strategies such as gamification in the teaching of molecular genetics to facilitate the cognitive and affective development and growth of the student is a way to develop the skills/abilities foreseen at BNCC. With the aim of investigating the implications of gamification in biology classes on the molecular genetics theme experienced with high school students, a gamified didactic sequence was created in five moments. The moment described in this article was a QRcode marathon, presenting favorable results for teaching-learning with strong engagement from the students, reaching the goals and contributing to the teaching practice.
\end{abstract}

Resumo. Associar estratégias inovadoras como a gamificação ao ensino de genética molecular para facilitar o desenvolvimento e crescimento cognitivo e afetivo do aluno é um meio para desenvolver competências/habilidades previstas na BNCC. Com o objetivo de investigar as implicações da gamificação em aulas de biologia sobre o tema de Genética Molecular vivenciada com alunos do ensino médio foi criada uma sequência didática gamificada em cinco momentos. $O$ momento descrito neste artigo foi a maratona QRcode, apresentando resultados favoráveis para o ensinoaprendizagem com forte engajamento por parte dos alunos, alcançando o objetivo e contribuindo para a prática docente.

\section{Introdução}

No espaço escolar Kruger e Ensslin (2013) afirmam que, coexistem diversos métodos de ensino que são usados pelos professores com o objetivo de transmitir e gerar conhecimento nos alunos. Dentre os métodos de ensino presentes na escola temos como um dos mais antigos e ainda largamente utilizado o método tradicional, na qual ao professor atribui-se o papel de detentor do conhecimento e ao aluno o sujeito dependente do conhecimento do seu mestre [Fujita 2007]. Por outro lado, as demandas da sociedade atual que chegam à escola são desafiadoras para o professor, que é levado a alinhar suas práticas aos anseios de uma sociedade que está em constante transformação. Assim, o professor se vê diante da necessidade de criar situações de ensino que conciliem às propostas curriculares vigentes aos interesses dos seus alunos. No mesmo sentido, o perfil do alunado vem se modificando, dado ao número crescente de estudantes que tem estado imerso em ciberespaços através dos games, downloads, chats de redes sociais, homepages criadas, ou não, por eles [Santos e Queiroz 2019]. 
$\mathrm{Na}$ medida em que o mundo se apropria e explora todo o potencial das tecnologias digitais a escola parece manter-se cristalizada em sua estrutura física, organizacional e formal. Esse cenário cristalizado pela escola termina por fomentar a percepção fragmentada da realidade apresentada através dos textos didáticos, geralmente por uma sequência pré-definida de aulas que por vezes se limita a estruturas curriculares lineares [Martins et al 2014]. Nesse sentido, as novas demandas sociais vão evidenciando que a metodologia tradicional já não atende mais as necessidades dos alunos no que tange ao seu desenvolvimento pessoal para a vida fora dos muros da escola. Como resposta, surge um comportamento mais apático nos alunos que tendem a ficarem cada vez mais desatentos e desinteressados pelos conteúdos curriculares e, consequentemente, participando menos nas aulas [Fujita 2007].

Vale ressaltar que em estudo desenvolvido por Moura et al (2013), verificaram que o ensino de biologia é muito abstrato e a aprendizagem fica ainda mais difícil, principalmente, quando o conteúdo abordado refere-se à área de genética, dada a falta de conexão com os fatos da realidade e o distanciamento dos anseios da sociedade na qual os alunos estão inseridos. Para as autoras, a dificuldade na compreensão do conteúdo biológico gera alienação por grande parte dos alunos, de modo relevante, quando os conteúdos estão ligados a tecnologia e aos produtos oriundos da genética. Assim, Moura et al (2013) sugerem que o ensino de biologia deva ser (re)pensado considerando a realidade dos alunos.

Nesse sentido, a contextualização dos conceitos de biologia, principalmente daqueles voltados à genética e biologia molecular é essencial para a (re)significação desses conteúdos os quais são considerados difíceis e desinteressantes para grande parte dos alunos [Moura et al 2013]. Vale destacar que, para Mano e Saravali (2016) a biologia lida a todo tempo com concepções abstratas especificamente quando os conteúdos estão ligados as células, a hereditariedade e ao "DNA", como por exemplo o conceito de síntese protéica, elevando em muito a necessidade do aluno se despreender do concreto. Tal fato pode ser a causa da dificuldade, ou até mesmo a impossiblidade de compreender a diversidade de conceitos, ou fenômenos ligados a biologia, especialmente aos conteúdos da genética molecular, não só pelos alunos, mas também, por parte dos professores [Mano e Saravali 2016]. Logo, aqueles conteúdos que fogem a nossa percepção imediata por serem microscópicos necessitam de um maior planejamento por parte do docente, tornando-se fundamental o uso de recursos e/ou estratégias didáticas que auxiliem na explanação e operacionalização desses conceitos [Moura et al 2013].

De acordo com a Base Nacional Comum Curricular (BNCC) não basta oferecer apenas o conchecimento científico produzido por outros, mas sobretudo é imprescindível que o Ensino de Biologia desenvolva competências e habilidades que permitam ao estudante lidar com as informações, entendê-las, (re)elaborá-las e desse modo, compreender o mundo e nele agir autonomamente usando os conhecimentos adquiridos através das aulas. Com efeito, para que a população compreenda as aplicações e implicações da genética molecular, é urgente que a ela seja dado o conhecimento básico sobre o tema através de práticas de ensino mais efetivas e significativas [Brasil 2017].

Diante disso, criar situações de ensino que estimulem os alunos a desenvolverem competências e habilidades para lidar melhor com sua realidade social é uma prioridade 
no atual cenário educacional. Para tanto, é exigido do docente um planejamento de ensino que valorize atividades práticas, produções individuais e coletivas, sistematizações progressivas de conteúdos e divulgação dos conhecimentos contruídos pelos alunos. Assim, inverter a forma tradicional de ensino buscando diminuir o tempo destinado às aulas expositivas (protagonizadas pelo professor) aumentando o tempo dedicado para atividades práticas e interdisciplinares (mediadas pelo professor e protagonizada pelos alunos) é essencial para promover vivências pedagógicas no âmbito das metodologias ativas [Silva 2015].

Segundo Rocha e Lemos (2014), na tentativa de minimizar o descompasso entre as práticas pedagógicas e as novas demandas sociais, algumas escolas têm buscado (re)pensar suas formas de ensino e organização curricular, incorporando as metodologias ativas com a intenção de aproximar teoria/prática e trazer uma dinâmica diferente para a aprendizagem escolar. Para os autores, as metodologias ativas procuram contribuir para a motivação autônoma, na medida em que têm o potencial de despertar a curiosidade ao tempo em que os alunos são imersos na teorização e, assim, vão trazendo elementos novos que ainda não haviam sido considerados nas aulas ou sequer previstos anteriormente pelo professor [Rocha e Lemos 2014].

Para Silva et al (2018) as metodologias ativas terminam por promover um comportamento mais participativo nos alunos ao passo em que são apresentados a desafios/problemas cujas soluções não tem uma resposta pronta ou única e que muitas vezes exigem o desenvolvimento de projetos, gerando, com isso, oportunidades para que eles sejam protagonistas na construção do seu conhecimento. Desse modo, o papel de mediador na interação do aluno com o contéudo estudado deve ser assumido pelo professor, sendo ele determinante na condução dos alunos rumo a jornada do saber [Borges e Alencar 2014]. Dentre as estratégias possíveis para a implantação das metodologias ativas em sala de aula, temos a gamificação, a qual se utiliza da dinâmica dos jogos para potencializar a aprendizagem de conteúdos escolares pelos estudantes [Kapp 2012]. Assim, de acordo com Santos e Queiroz (2019), acreditamos que

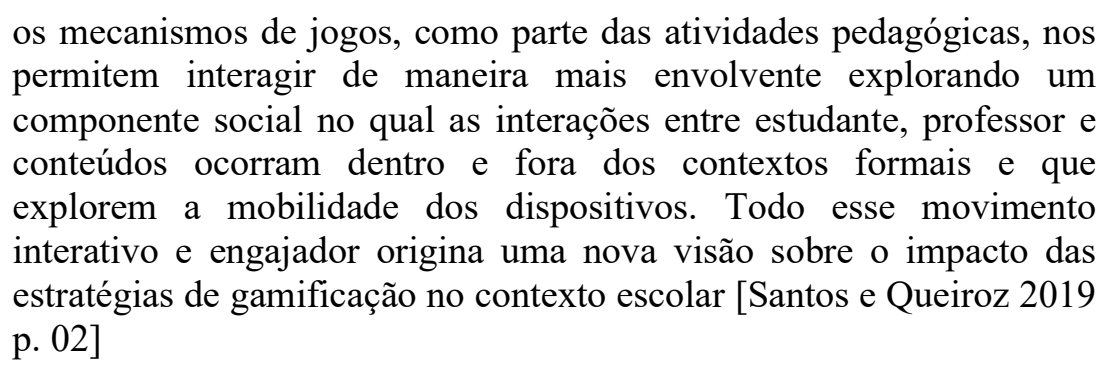

Muitos são os autores, como Martins et al (2014) e Santos e Queiroz (2019), que têm como proposta o uso de jogos e de seus elementos na aprendizagem de conceitos e no desenvolvimento de competências e habilidades em diferentes áreas do conhecimento. Outros autores, como Alves (2014); Colombo (2017) e Santos et al (2019), tem investido em pesquisas em torno da relação dos jogos com a motivação e o engajamento dos indivíduos. Como observa Martins et al (2014), a gamificação caracteriza-se como uma metodologia ativa sendo um fenômeno que surge da popularidade dos jogos digitais, fazendo uso de recursos, estratégias e lógica dos games sem efetivamente usá-los. Adicionalmente, Santos et al (2019) comentam que as mecânicas de jogos, quando bem planejadas, podem gerar motivação nos alunos que participam de aulas gamificadas. 
Para Santos et al (2019), a motivação é peça-chave para que se possa atingir os objetivos da aprendizagem e, consequentemente, conseguir que os alunos alcancem as competências e habilidades esperadas. Segundo Gil et al (2012), a motivação está relacionada a ação de aguçar o interesse sobre alguma coisa e que será produzida no sujeito de modo a gerar alguma reação. Sobre o conceito de motivação, Vianna et al (2013), afirmam que em sua base estão as experiências vividas pelos sujeitos e a ressignificação que fazem delas através do incentivo à "criatividade, ao pensamento autônomo e propiciando bem-estar ao sujeito" (p. 30). De acordo com a literatura, a motivação pode ser classificada em dois tipos: (1) Motivação extrínseca, cujas fontes são externas e mobilizam o sujeito para realizar tarefas em troca de alguma recompensa ou para evitar uma punição e, cessando com o término do que havia sido programado para fazer e; (2) Motivação intrínseca, cuja origem está em fatores internos ao indivíduo e relaciona-se com seus interesses, gostos e na satisfação pessoal, não havendo necessidade de recompensas, logo, a tarefa deixa de ser uma obrigação [Poffo 2016].

De modo geral, para Santos et al (2019), planejar aulas em contexto gamificado pode criar as condições necessárias para que os alunos se sintam motivados a estarem na escola desenvolvendo as competências e habilidades necessárias à vida em sociedade e que estão previstas na BNCC. Para além das habilidades e das aprendizagens específicas de cada área do conhecimento e etapa escolar descrita na BNCC, há competências gerais que colaboram para uma formação integral do aluno de modo a permitir que ele construa seu projeto de vida, protagonize seu processo de aprendizagem e dê continuidade aos seus estudos. Nesse sentido, propor aulas gamificadas que se alinhem com as competências gerais e específicas da BNCC, nos parece ser um ótimo meio para estimular ações educativas mais inovadoras e aprendizagens mais dinâmicas e autônomas nos alunos quando comparadas com um ensino mais tradicional. Dentre as referidas competências gerais, é possível vislumbrar, através do planejamento de ensino gamificado em ciências/biologia, o atendimento a grande parte delas, como:

(1) Valorizar e utilizar os conhecimentos historicamente construídos (...) para entender e explicar a realidade (...); (2) Exercitar a curiosidade intelectual e recorrer à abordagem própria das ciências (...); (3) Utilizar diferentes linguagens verbal(...), corporal, visual, sonora e digital(...); (4) Compreender, empregar e criar tecnologias digitais de informação e comunicação de forma significativa, para se acessar informações, resolver problemas e exercer protagonismo(...); (5) Argumentar com base em fatos, dados e informações confiáveis, para formular, negociar e defender ideias, pontos de vista; (6) Exercitar a empatia, o diálogo, a resolução de conflitos e a cooperação, fazendo-se respeitar e promovendo o respeito ao outro(...) e; (7) Agir pessoal e coletivamente com autonomia, responsabilidade, flexibilidade(...) [Brasil 2017, p. 09-10].

Vale ressaltar que a expressão $Q R$ code se refere ao aplicativo denominado Quick Response Code ( $Q R$ Code), criado no Japão na década de 90 pela Denso-Wave empresa responsável pela produção de equipamentos automobilísticos [Vieira e Coutinho 2013]. Segundo Ribas et al (2017), o $Q R$ code funciona através de um código de barras 2D para leitura de alta velocidade, isto é, para respostas rápidas. Os autores comentam que o referido código foi criado para dar agilidade ao processo de catalogação de componentes automobilíticos da referida fábrica através da leitura rápida através de um equipamento digital. Se comparado ao código de barras comum, que 
armazena até 20 dígitos, fica evidente que o $Q R$ code tem uma capacidade de armazenamento muito maior, cerca de 7.089 caracteres e pode, assim, armazenar diversas categorias de dados como caracteres alfabéticos e numéricos, símbolos, dentre outros [Ribas et al 2017].

No âmbito educacional os $Q R$ codes passaram a ser usados de modo pontual por alguns professores mais destemidos, que viram neles uma forma de revolucionar o ensino escolar. Vieira e Coutinho (2013), destacam que o $Q R$ code utilizados na educação ajusta-se aos pressupostos do Mobile Learning, ou seja, o uso de dispositivo móvel para o processo de aprendizagem. As autoras comentam que ao associar o $Q R$ code ao uso dos dispositivos móveis é possível mudar a dinâmica dos processos de ensino e aprendizagem em sala de aula ligando o mundo físico ao virtual e favorecendo a interação, o trabalho colaborativo, assim como, a confiança e a autoestima dos alunos. Adicionalmente, as tecnologias do Mobile Learning, como $Q R$ code, podem oferecer

uma nova e emocionante oportunidade para que os professores coloquem os alunos em ambientes ativos de aprendizagem que são desafiadores, fazendo as suas próprias contribuições, partilhando ideias, explorando, investigando, experimentando e discutindo, porém, não pode ser deixado sem controle e sem suporte [Vieira e Coutinho 2013, p. 78].

Nesse contexto, o objetivo do artigo busca descrever e analisar as implicações da atividade Maratona QRcode para a aprendizagem e motivação de alunos do $3^{\circ}$ ano do Ensino Médio de uma Escola Pública da Rede Estadual de Ensino de Pernambuco no ensino de genética molecular. A Maratona QRcode consistiu no momento final de uma Sequência Didática (SD) Gamificada sobre genética molecular realizada no âmbito do Mestrado Profissional no Ensino de Biologia em Rede Nacional-PROFBIO. A SD Gamificada foi o produto resultante da pesquisa realizada durante o referido curso.

Desse modo, a Maratona QRcode tornou-se essencial em um cenário de aulas gamificadas com uso de dispositivo móvel (smartphone) para potencializar a aprendizagem conceitual nos alunos, assim como, desenvolver competências e habilidades alinhadas com a BNCC. Como resultado da aplicação dessa atividade esperamos que os alunos consolidem os conceitos relativos à genética molecular, bem como, possam se sentir mais estimulados e engajados nas aulas de biologia.

\section{Material e Métodos}

A atividade aqui apresentada é um fragmento de intervenção didática proposta no âmbito do curso de Mestrado Profissional no Ensino de Biologia em Rede NacionalPROFBIO. A intervenção tratou da aplicação de uma Sequência Didática Gamificada que surgiu com base nos pressupostos da metodologia da pesquisa-ação apresentada por Michel Thiollent. $\mathrm{Na}$ abordagem da referida metodologia de pesquisa a participação colaborativa dos envolvidos é essencial para a resolução do problema coletivo [Thiollent 1986]. Para tanto, a docente também atuou de modo colaborativo, como sujeito da pesquisa, envolvendo-se nas atividades realizadas junto aos seus alunos.

Os alunos que participaram da atividade com o $Q R$ code fazem parte da referida pesquisa e compõem uma turma do terceiro ano de escola da Rede Estadual de Ensino em Cortês - Pernambuco, com idades entre 15 e 17 anos, totalizando 42 alunos. A Sequência Didática (SD) construída e executada nessa pesquisa contemplou cinco 
momentos, dentre eles, a Maratona QRcode que será descrita desde a sua construção em etapas (Tabela 1) até a análise de seus resultados.

Tabela 1. Etapas do jogo Maratona QRcode

\begin{tabular}{|l|l|}
\hline \multicolumn{1}{|c|}{ Etapa } & \multicolumn{1}{c|}{ Descrição } \\
\hline Elaboração do Jogo Maratona QRcode & Construção dos QRcode-questão e QRcode-pistas. \\
\hline Seleção do Material Utilizado & Folhas A4 impressas com os QR codes; Smartphones. \\
\hline Leitor de QR code & $\begin{array}{l}\text { Download do leitor de QRcode, disponível gratuitamente na } \\
\text { loja de aplicativos do smartphone. }\end{array}$ \\
\hline Divisão da turma & Estudantes divididos em 4 grupos e 1 líder em cada grupo. \\
\hline Aplicação do Jogo Maratona QRcode. & Vivência do jogo. \\
\hline Encerramento & Premiação dos grupos $\left(1^{\circ}\right.$ ao $\left.4^{\circ}\right)$ \\
\hline
\end{tabular}

Previamente separados em quatro grupos, com um líder por grupo, os alunos foram orientados sobre a fazerem o download de um aplicativo de leitura de $Q R$ code (gratuitamente disponível no Play Store) em seus smartphones (01 dispositivo móvel para cada grupo). O líder do grupo portava o smartphone e mais duas pessoas da sua equipe realizaram os desafios. Cada grupo foi desafiado a responder seis questões relativas à genética molecular e através de seis pistas (Tabela 2) impressas em formato $Q R$ code foram conduzidos a buscarem os desafios em diferentes pontos da escola (diretoria, secretaria, sala do professor, cozinha, biblioteca e sala de aula). Vale ressaltar, que todos os grupos responderam as mesmas perguntas e foram aos mesmos lugares, todavia, em uma ordem particular. Adicionalmente, alunos de outras turmas foram convidados para serem monitores da atividade e foram distribuídos nos locais onde estavam os $Q R$ codes-questão para, assim, conferir as respostas faladas e liberar os estudantes para o próximo QRcode-pista.

A atividade teve início em sala de aula com o fornecimento pela docente do primeiro QRcode-questão aos alunos representantes de cada grupo e para aqueles que respondiam corretamente era fornecido um QRcode-pista com a descrição do lugar do próximo QRcode-questão e, assim, sucessivamente. Os estudantes ao responderem o último QRcode-questão recebiam o último QRcode-pista, onde o lugar final para todos os grupos foi a sala de aula, pois assim todos puderam voltar ao ponto de início e finalizar o jogo. A ordem de chegada determinou a pontuação recebida por cada grupo $(200,150,100$ e 50 pontos). Caso algum(ns) grupo(s) não finalizasse(m) a atividade não pontuava $(\mathrm{m})$.

Tabela 2. Perguntas e respostas da Maratona-QRcode.

\begin{tabular}{|l|c|c|c|}
\hline \multicolumn{1}{|c|}{ QRcode-questão (Pergunta) } & $\begin{array}{c}\text { QRcode-questão } \\
\text { (Resposta) }\end{array}$ & $\begin{array}{c}\text { QRcode-pista } \\
\text { (Pergunta) }\end{array}$ & $\begin{array}{c}\text { QRcode-pista } \\
\text { (Resposta) }\end{array}$ \\
\hline Qual o papel do RNA transportador? & $\begin{array}{c}\text { Transportar o } \\
\text { aminoácido para o } \\
\text { ribossomo durante } \\
\text { a tradução }\end{array}$ & $\begin{array}{c}\text { Têm muitos } \\
\text { livros. }\end{array}$ & Biblioteca \\
\hline $\begin{array}{l}\text { Quem foi o biólogo, botânico, monge agostiniano e } \\
\text { meteorologistaque de 1858 à 1866, realizou pesquisas sobre } \\
\text { hereditariedade, observando e estudando plantas? }\end{array}$ & Gregor Mendel & $\begin{array}{c}\text { Onde se } \\
\text { preparam as } \\
\text { refeições. }\end{array}$ & Cozinha \\
\hline
\end{tabular}




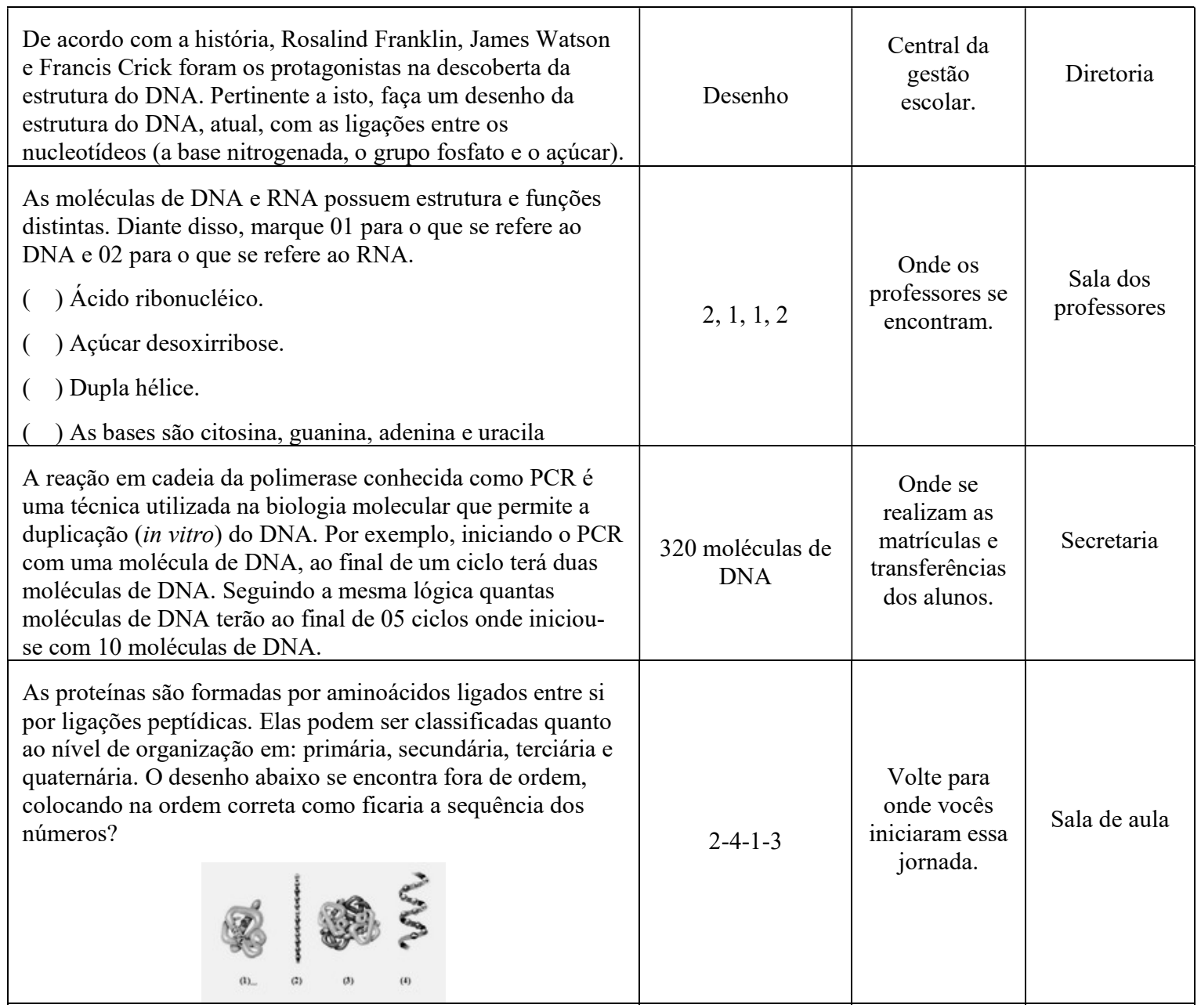

\section{Resultados e Discussão}

Esse momento da SD Gamificada teve início com a explicação da docente sobre as instruções do jogo e solicitação aos líderes dos grupos da indicação de dois colegas para acompanhá-lo na procura dos locais e respostas dos $Q R$ codes, evitando movimentação desnecessária de alunos pela escola. Visitados todos os locais das pistas fornecidas e respondidas às questões os alunos puderam retornar para a sala de aula e a Maratona QRcode foi dada como concluída (Figura 1). 


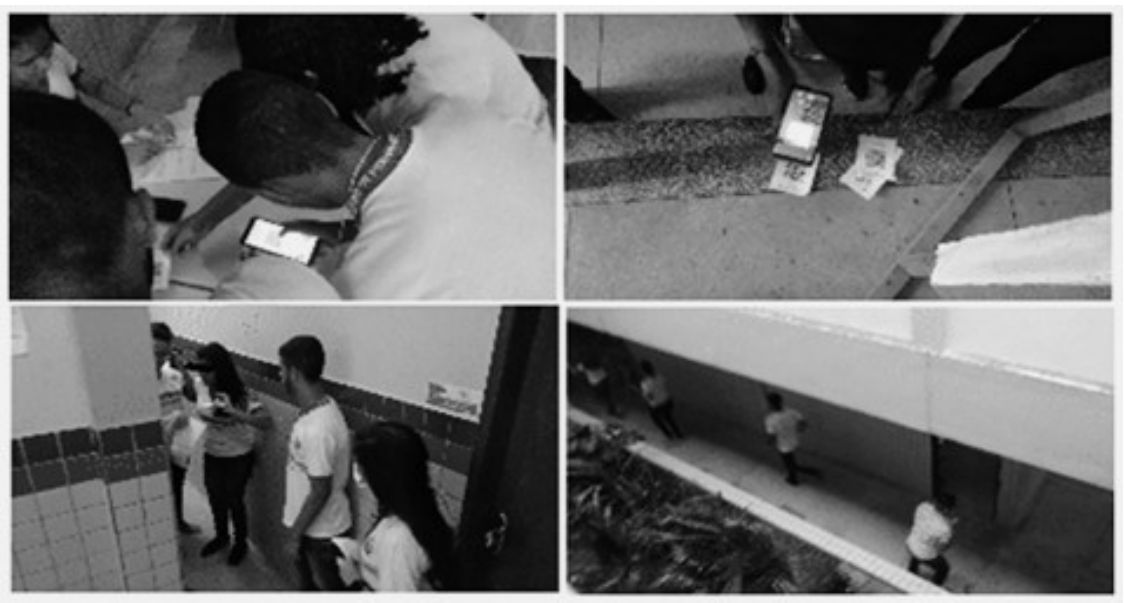

Figura 1. Realização do jogo Maratona QRcode.

O primeiro grupo a concluir a tarefa foi o grupo vermelho sendo o mais rápido em entregar todos os $Q R$ codes questão com todas as respostas corretas. Logo em seguida chegou o grupo amarelo, o grupo azul e para terminar o desafio o grupo verde chegou à sala de aula. Para encerrar esse momento, as perguntas e respostas de cada $Q R$ code foram socializadas para toda turma e em seguida foi feita a premiação de cada grupo de forma proporcional à sua ordem de colocação. Todos os grupos receberam prêmios, uma vez que, estavam engajados na realização da tarefa, ficando nítida a motivação extrínseca por parte dos alunos dado que esperavam uma recompensa ao final da atividade [Poffo, 2016]. Foi observado pela docente os sinais de motivação intrínseca, pois estavam estimulados a continuar e finalizar pelo prazer que o jogo fornecia, assim aprendiam jogando e retratavam alegria e satisfação pessoal ao concluir a tarefa da melhor forma que podiam.

A respeito das competências alcançadas da BNCC temos: investigar situações problemas; conhecer diferentes formas de obter informações; apresentar de forma organizada o que foi aprendido, capacitando o aluno a lidar com as informações e compreendê-las, assim, a BNCC entende que essas competências são fundamentais para uma formação integral de cidadãos críticos, autônomos e criativos. De fato, o desafio organizado de forma gamificada permitiu estimular o processo de cooperação, uma vez que precisavam trabalhar juntos para a conclusão da tarefa [Brasil 2017].

Quanto a participação, foi percebido pela docente que os alunos estiveram comprometidos, entusiasmados e receptivos, demonstrando um forte engajamento e motivação, o que leva a concluir que o grau de envolvimento do aluno tem implicações diretas no seu processo de aprendizagem. Desse modo, a vivência do jogo Maratona QRcode fomentou um aprendizado mais dinâmico, motivador e lúdico dos conceitos de genética molecular, possibiltando um maior engajamento dos alunos, uma vez que participaram mais ativamente durante o desafio.

\section{Considerações Finais}

Perante a proposta de agregar as competências da BNCC propostas para o Ensino de Ciências da Natureza é possível que o docente fomente aprendizagens em diversas áreas do conhecimento ao usar estratégias baseadas nos princípios da gamificação de maneira motivadora, agradável e divertida e aproximar os alunos do conhecimento científico. 
Nesse contexto de aulas gamificadas, em particular em relação ao jogo Maratona QRcode, buscou-se contribuir para a aprendizagem de conteúdos conceituais e apontar novos caminhos metodológicos para o ensino de genética molecular.

Com a aplicação da Maratona QRcode foi possível observar que os elementos da gamificação podem proporcionar momentos de maior motivação e engajamento por parte dos alunos na sala de aula, sendo assim, acredita-se que este trabalho alcançou o objetivo proposto com bons níveis na aprendizagem alinhando-se com as competências da BNCC pretendidas. Por fim, concluiu-se que o jogo Maratona QRcode se mostrou possível de ser aplicada e com potencial de ser replicada em aulas de outros professores de biologia para o ensino de genética molecular, sendo um instrumento eficaz que pode auxiliar no processo de ensino-aprendizagem, motivação e engajamento dos alunos em sala de aula.

\section{Referências}

Alves, Flora. (2014). Gamification: como criar experiências de aprendizagem engajadoras um guia completo do conceito à prática. 1 ed. São Paulo: DVS Editora.

Brasil. Base Nacional Comum Curricular: Ensino Médio. Brasília: MEC/Secretaria de Educação Básica, (2017). Disponível em $<$ http://portal.mec.gov.br/index.php?option $=$ com_docman\&view $=$ download\&alias $=8$ 5121-bncc-ensino-medio\&category_slug=abril-2018-pdf\&Itemid=30192> Acesso: nov/2019.

Borges, T. S. e Alencar, G. (2014). Metodologias ativas na promoção da formação crítica do estudante: ouso das metodologias ativas como recurso didático na formação crítica do estudante do ensino superior. Cairu em Revista. Ano 03, n. 04, p. 119-143.

Colombo; R. (2017). A Gamificação como estratégia para o aprendizado de jornalismo. $40^{\circ}$ Congresso Brasileiro de Ciências da Comunicação - Curitiba - PR. Disponível $<$ http://portalintercom.org.br/anais/nacional2017/resumos/R12-2725-1.pdf $>$ Acesso: $\mathrm{Mar} / 2020$.

Fujita, O. M. (2007). Do presencial tradicional ao virtual: planejamento e mudança de postura. In: Congresso Internacional de Educação à Distância. Universidade Estadual Paulista. Anais... Pres. Prudente-SP.

Gil, Eric de S. et al. (2012). Estratégias de ensino e motivação de estudantes no ensino superior. Vita et Sanitas, Trindade-Go, n.06.

Kapp, K. (2012) The Gamification of Learning andInstruction: Game-based Methods and Strategies for Training and Education. Pfeiffer.

Kruger, L. M. e Ensslin, S. R. (2013). Método Tradicional e Método Construtivista de Ensino no Processo de Aprendizagem. Revista Organizações em contexto. São Bernardo do Campo, Vol. 9, n. 18, jul.-dez.

Mano, A. M. P. e Saravali, E. G. (2016). Conteúdos difíceis de ensinar na perspectiva de professores de ciências. In: III Congresso Nacional de Formação de Professores e do Águas de Lindóia. Anais... São Paulo: UNESP/Prograd, 2016. v. 3. p. 2275-2284. 
Martins, T. M. de O. et al (2014). A Gamificação de conteúdos escolares: uma experiência a partir da diversidade cultural brasileira. Anais... X Seminário Jogos Eletrônicos, Educação e Comunicação.

Moura, J. et al (2013). Biologia/Genética: O ensino de biologia, com enfoque a genética, das escolas públicas no Brasil - breve relato e reflexão. Revista Semina Ciências Biológicas e da Saúde, Londrina, v. 34, n. 2, p. 167-174.

Navarro, G. (2013). Gamificação: a transformação do conceito do termo jogo no contexto da pós-modernidade. CELACC/ECA - USP.

Poffo, M. (2016). Utilização da gamificação para motivar a aprendizagem: um estudo de caso em engenharia de software. Dissertação (Mestrado Acadêmico em Computação Aplicada). Universidade do Vale do Itajaí.

Ribas, A. C. et al. (2017). O uso do aplicativo QR code como recurso pedagógico no processo de ensino e aprendizagem. Revista Ensaios Pedagógicos, v.7, n.2, Jul/Dez.

Rocha, H. M. e Lemos, W. de M. (2014). Metodologias ativas: do que estamos falando? Base conceitual e relato de pesquisa em andamento. IX Simpósio Padagógico e Pesquisas em Comunicação. Disponível em <https://www.aedb.br/wpcontent/uploads/2015/05/41321569.pdf $>$. Acesso: Mai/2020.

Santos, J. T. G. et al. (2019). A Gamificação como Metodologia para o Desenvolvimento de Competências Gerais da BNCC. XXV Workshop de Informática na Escola. Anais... Disponível em <https://www.brie.org/pub/index.php/wie/article/view/8577/6142> Acesso: Mai/2020.

Santos, D. F. dos e Queiroz, C. V. (2019). Harry Potter no ensino de línguas: uma proposta de gamificação em ambientes formais de aprendizagem. Revista Tecnologias na Educação. Ano 11-número/vol. 32 - Dez/2019 - Edição Temática XIII - $3^{\circ}$ Simpósio Internacional sobre Games, Gamification e Tecnologias na Educação- UFSM.

Silva, A. F. (2015). Uma proposta de sequência didática para o ensino da cinemática através da robótica educacional. Dissertação (Universidade Federal de Goiás).

Silva, J. B. et al. (2018). Tecnologias digitais e metodologias ativas na escola: o contributo do Kahoot para gamificar a sala de aula. Revista Thema. v. 15, n. 2, p. 780-791.

Thiollent, M. (1986). Metodologia da pesquisa-ação. Coleção "Temas básicos de..." Editora Cortez. São Paulo-SP.

Vieira, L. S. e Coutinho, C. P. (2013). Mobile learning: perspectivando o potencial dos códigos QR na educação. In: Conferência Internacional de TIC na Educação, 8, Challenges, 2013. Braga, Portugal. Anais ... Braga: Universidade do Minho, 2013. p. 73-91. 